\title{
Deficits in Eye Movement Control in Children With Fetal Alcohol Spectrum Disorders
}

\author{
Courtney R. Green, Douglas P. Munoz, Sarah M. Nikkel, and James N. Reynolds
}

\begin{abstract}
Background: Prenatal exposure to alcohol can result in a spectrum of adverse developmental outcomes in offspring, collectively termed fetal alcohol spectrum disorders (FASD). Deficits in executive function - the psychological processes involved in controlling voluntary goal-oriented behavior-are prevalent in FASD. Oculomotor tasks have been designed as highly sensitive tools to evaluate components of executive function. Because of the extensive overlap in the brain areas controlling eye movements and those affected in FASD, we hypothesized that individuals with FASD display specific neurobehavioral abnormalities that can be quantified with eye movement testing.

Methods: Subjects (8-12 years old) were instructed to look either toward (prosaccade) or away from (antisaccade) a stimulus that appeared in the peripheral visual field. Two fixation conditions were used. In the gap condition, the central fixation point (FP) was removed before the appearance of the peripheral stimulus; in the overlap condition, the FP remained illuminated. Saccadic reaction times (SRTs, time from stimulus appearance to saccade initiation), direction errors (saccades made in the incorrect direction relative to instruction), and express saccades (short-latency: SRT $=90-140 \mathrm{~ms}$ ) were measured to assess automatic and volitional saccade control.

Results: Compared with controls, FASD children had elongated reaction times, excessive direction errors, and no express saccades. Metric analysis of correct prosaccades revealed a trend toward increased saccadic duration and decreased saccadic velocity in FASD subjects.

Conclusion: These results reflect deficits in executive function and motor control, and are consistent with dysfunction of the frontal lobes, possibly due to disrupted inhibitory mechanisms. Therefore, eye movement tasks may be powerful and easy tools for assessing executive function deficits in FASD.
\end{abstract}

Key Words: FASD, Eye Movement, Diagnostic Tool, Saccade, Executive Function.

$\mathrm{T}$ HE MAJOR CONSEQUENCE of prenatal ethanol exposure is fetal alcohol syndrome (FAS) (Astley and Clarren, 2000; Chudley et al., 2005; Clarren and Smith, 1978). Fetal alcohol syndrome is characterized by growth restriction (both prenatal and postnatal), craniofacial dysmorphology (i.e., indistinct philtrum, short palpebral fissure), and central nervous system dysfunction. Recently, the term fetal alcohol spectrum disorders (FASD) has been

From the Centre for Neuroscience Studies, Queen's University, Kingston, ON, Canada (CRG, DPM, JNR); the Department of Pharmacology and Toxicology, Queen's University, Kingston, ON, Canada $(J N R)$; the Department of Physiology, Queen's University, Kingston, $O N$, Canada (DPM); the Department of Psychology, Queen's University, Kingston, ON, Canada (DPM); and the Department of Genetics, Children's Hospital of Eastern Ontario, Ottawa, ON, Canada (SMN).

Received for publication August 17, 2006; accepted December 2, 2006.

This research was supported by operating grants from the Canadian Institutes of Health Research (JNR, DPM) and the Botterell Foundation of Queen's University (JNR), and by the Canada Research Chair Program (DPM). CRG is the recipient of an Ontario Graduate Scholarship in Science and Technology.

Reprint requests: James N. Reynolds, Department of Pharmacology and Toxicology, Queen's University, Kingston, ON, Canada K7L 3N6; Fax: 613-533-6412; E-mail: jnr@post.queensu.ca

Copyright (C) 2007 by the Research Society on Alcoholism.

DOI: 10.1111/j.1530-0277.2006.00335.x introduced and widely adopted as an umbrella term, which includes all disorders relating to prenatal alcohol exposure (Koren et al., 2003). Although the terminology has been clarified, an accurate diagnosis still remains a significant clinical challenge due largely to the absence of objective diagnostic tools, and particularly in cases where the craniofacial dysmorphology is absent, but the cognitive deficits are still prevalent.

Executive functions consist of those capacities that enable a person to engage successfully in independent, purposive, self-serving behaviors (Funahashi, 2001; Lezak, 1995), and deficits in these functions are now recognized as a hallmark of prenatal ethanol exposure. Individuals with FASD exhibit a range of deficits in executive function, including problems with flexibility of thought, planning, impulsivity, verbal reasoning, task switching, and working memory (Rasmussen, 2005). Indeed, several studies have documented deficits in executive function in children with a history of prenatal ethanol exposure, but without the facial dysmorphology of FAS (Connor et al., 2000; Mattson et al., 1999; Schonfeld et al., 2001). This finding reinforces the view that of the 3 key diagnostic features, it is the deficits in brain function that are of primary importance (Chudley et al., 2005). Thus, further research into the specific pattern of executive function deficits in the FASD 
population, using objective and consistent measurement tools, is needed (Rasmussen, 2005).

One tool that has been used extensively to study deficits in motor control, working memory, and executive function associated with various neurodevelopmental and neurodegenerative disorders is saccadic eye movements (Guitton et al., 1985; Leigh and Kennard, 2004; Leigh and Zee, 1999; Munoz and Everling, 2004; Munoz et al., 2007). The underlying neural circuitry that controls saccadic eye movements is now understood to an extent that higher cognitive function can be probed using saccade paradigms, and these tests may be used to assess specific deficits in executive function in patients with FASD. Thus, oculomotor tasks may provide a unique opportunity to probe the effects of prenatal alcohol exposure on brain and behavior relationships in a way that other cognitive tasks cannot.

There is considerable overlap in the structures that are responsible for producing a saccade (Leigh and Kennard, 2004; Leigh and Zee, 1999; Munoz and Everling, 2004), and those that are damaged by prenatal alcohol exposure, including the frontal lobes, thalamus, basal ganglia, and cerebellum (Kopera-Frye et al., 1996; Mattson et al., 2001; Rasmussen, 2005; Sowell et al., 2002a). Damage to these structures can affect saccade production and these deficits are measurable and quantifiable.

An important feature of human behavior is the ability to respond flexibly to different environmental stimuli. These attributes can be investigated in specific oculomotor paradigms. Subjects can be instructed to look toward a visual stimulus (Fig. 1A, prosaccade task, requires automatic response) or suppress this automatic response and look away from the stimulus (Fig. 1B, antisaccade task, requires volitional response) (Hallett, 1978; Munoz and Everling, 2004). The prosaccade task assesses basic sensorimotor reflexes, as well as the ability to maintain visual fixation, whereas the antisaccade task assesses voluntary motor control; that is, the ability to suppress the automatic response toward the peripheral stimulus in favor of an

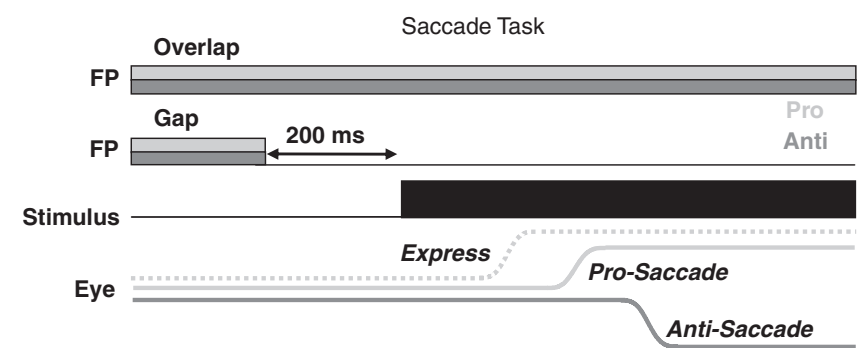

Fig. 1. In the prosaccade task, the subject was instructed to look from the central fixation point (FP) toward the eccentric stimulus. In the antisaccade task, the subject was instructed to look away from the eccentric stimulus to the opposite side. In both tasks, the state of fixation before the saccade was manipulated. In the overlap condition, the FP remained illuminated while the stimulus appeared. In the gap condition, the FP disappeared for $200 \mathrm{~ms}$ before the stimulus appeared. In both conditions, the saccadic reaction time was measured from the time of stimulus appearance to the initiation of the first saccade. alternate behavior (Munoz and Everling, 2004). In addition, to gain further insight into the process of response inhibition, 2 different fixation conditions are frequently used. In the gap condition, the central fixation point (FP) is extinguished before the appearance of the peripheral stimulus. Subjects experience greater difficulty in inhibiting the prepotent response under the gap condition. In the overlap condition, the central FP remains illuminated while the peripheral target appears, making it easier for subjects to suppress the unwanted movement toward the peripheral stimulus. Because cognitive function includes the ability to voluntarily inhibit prepotent responses, guide goal-directed behavior, and use working memory, oculomotor tasks can thus be used to dissociate these different cognitive abilities.

Saccadic eye movement experiments have been performed over a wide range of ages, including children (Fischer et al., 1997; Klein et al., 2003; Munoz et al., 1998; Salman et al., 2006). This technique is noninvasive and easy to administer, making it highly suitable to assess executive function in the FASD population. Furthermore, saccadic eye movement experiments have been used to characterize a variety of neuropsychological and neurodegenerative diseases (Leigh and Kennard, 2004; Munoz et al., 2007), including schizophrenia (Currie et al., 1993; Zanelli et al., 2005), attention-deficit hyperactivity disorder (ADHD; Armstrong and Munoz, 2003; Munoz et al., 2003; O'Driscoll et al., 2005), Parkinson's disease (Chan et al., 2005; Crawford et al., 1989; Kimmig et al., 2002; Le Heron et al., 2005), Tourette's syndrome (TS) (LeVasseur et al., 2001), and Alzheimer's disease (Crawford et al., 2005). The existing knowledge from these groups may assist with the identification of traits that are unique to FASD.

The aim of this study was 2 -fold. The first objective was to determine whether saccades could be measured in children with FASD using prosaccade and antisaccade tasks, as these experiments have not been previously conducted in this clinical population. The second objective was to quantify the control of automatic and volitional responses using prosaccade and antisaccade tasks. It was hypothesized that subjects with FASD would have no trouble in performing saccadic eye movement experiments; however, based on the known deficits in frontal lobe function, these children were expected to produce saccades with increased saccadic reaction times (SRT) and make more direction errors in the antisaccade task compared with control children. In addition, because of known brainstem and cerebellar dysfunction, children with FASD were expected to produce significant deficits in saccade metrics (amplitude, velocity, and duration). These tasks provide an excellent method for quantifying and comparing objectively the responses of children with FASD to those of control subjects, and may provide insight into the specific types of brain damage associated with prenatal ethanol exposure. 
Preliminary versions of these data have been presented in abstract form (Green et al., 2004, 2005, 2006).

\section{MATERIALS AND METHODS}

\section{Participants}

All experimental procedures were reviewed and approved by the Queen's University Human Research Ethics Board. We selected children with FASD, as determined by a clinical geneticist and according to the 4-digit diagnostic code (Astley and Clarren, 2000). Ten children with FASD ( 4 males, 6 females; $9.8 \pm 0.4$ years of age, range 8-12 years) were recruited and compared with 12 age-matched control subjects ( 6 males, 6 females; $10.0 \pm 0.3$ years of age, range 8-12 years). Of the 10 children with FASD, 8 were medicated for behavioral symptoms relating to their comorbidities (Table 1). Children were tested off their medication, such that their last daily dose was administered the day before arriving at the lab, recognizing that for some pharmacological agents this was not a sufficient wash-out period. Agents that were most likely to interfere with testing were stimulant medications that have a relatively short half-life $(\sim 6-12$ hours) (Katzung, 1998) and for which the overnight wash-out period was sufficient. The contribution of each drug therapy could not be addressed in this study due in part to sample size, but more precisely due to the extensive differences that exist between medication regimens and treatment history. All control subjects had no known neurological, psychiatric, or visual disorders, other than requiring corrective lenses, which were worn if needed throughout the experiments. Parents and/or legal guardians were informed of the nature of the study and provided written consent on behalf of the participants. All subjects completed one, 1-hour session and were paid $\$ 10$.

\section{Saccade Task}

All participants performed the saccade task (Fig. 1), consisting of 1 block of prosaccade trials, followed by 2 blocks of antisaccade

Table 1. FASD Subject Information

\begin{tabular}{|c|c|c|c|c|c|c|}
\hline Subject & IOM & Sex & Age & Medication & Comorbid symptoms & Education history \\
\hline 1 & FAE & $\mathrm{F}$ & 10 & $\begin{array}{l}\text { Lithium } \\
\text { Risperdal } \\
\text { Prozac }\end{array}$ & $\begin{array}{l}\text { Anxiety disorder } \\
\text { Depression } \\
\text { Bipolar mood disorder } \\
\text { Oppositional defiant disorder }\end{array}$ & Resource help \\
\hline 2 & ARND & $\mathrm{F}$ & 11 & $\begin{array}{l}\text { Risperdal } \\
\text { Dexedrine }\end{array}$ & ADHD & Suspension \\
\hline 3 & ARND & M & 12 & $\begin{array}{l}\text { Risperdal } \\
\text { Dexedrine }\end{array}$ & $\begin{array}{l}\text { ADHD } \\
\text { Depression } \\
\text { Oppositional defiant disorder }\end{array}$ & $\begin{array}{l}\text { Suspension } \\
\text { Learning disability } \\
\text { Resource help } \\
\text { Special education } \\
\text { Special program } \\
\text { Special class }\end{array}$ \\
\hline 4 & ARND & $\mathrm{F}$ & 10 & $\begin{array}{l}\text { Risperdal } \\
\text { Clonidine } \\
\text { Epival }\end{array}$ & $\begin{array}{l}\text { ADHD } \\
\text { Oppositional defiant disorder } \\
\text { Neurological disorder }\end{array}$ & $\begin{array}{l}\text { Learning disability } \\
\text { Resource help } \\
\text { Special education } \\
\text { Special class }\end{array}$ \\
\hline 5 & FAS & $\mathrm{F}$ & 10 & Concerta & ADHD & $\begin{array}{l}\text { Learning disability } \\
\text { Resource help } \\
\text { Special education } \\
\text { Special program }\end{array}$ \\
\hline 6 & FAS & $\mathrm{F}$ & 10 & NA & NA & $\begin{array}{l}\text { Learning disability } \\
\text { Resource help }\end{array}$ \\
\hline 7 & FAE & $\mathrm{F}$ & 9 & Ritalin & ADHD & $\begin{array}{l}\text { Suspension } \\
\text { Resource help } \\
\text { Special education } \\
\text { Special program } \\
\text { Special class }\end{array}$ \\
\hline 8 & ARND & M & 8 & $\begin{array}{l}\text { Ritalin } \\
\text { Clonidine }\end{array}$ & $\begin{array}{l}\text { ADHD } \\
\text { Conduct disorder }\end{array}$ & $\begin{array}{l}\text { Suspension } \\
\text { Learning disability } \\
\text { Special education } \\
\text { Special program } \\
\text { Special class }\end{array}$ \\
\hline 9 & FAE & M & 9 & $\begin{array}{l}\text { Concerta } \\
\text { Risperdal }\end{array}$ & $\begin{array}{l}\text { ADHD } \\
\text { Developmental delay }\end{array}$ & $\begin{array}{l}\text { Learning disability } \\
\text { Resource help } \\
\text { Special education } \\
\text { Special program } \\
\text { Special class }\end{array}$ \\
\hline 10 & FAS & M & 9 & NA & ADHD & $\begin{array}{l}\text { Suspension } \\
\text { Learning disability } \\
\text { Resource help } \\
\text { Special education } \\
\text { Special program } \\
\text { Special class }\end{array}$ \\
\hline
\end{tabular}

IOM, Institute of Medicine; FAE, fetal alcohol effects; ARND, alcohol-related neurodevelopmental disorder; FAS, fetal alcohol syndrome; ADHD, attention-deficit hyperactivity disorder; NA, not applicable. 
trials, each block consisting of 100 trials. Subjects received breaks and refreshments between blocks. Participants were seated in a dentist chair, while in complete darkness facing the center of a translucent screen located $100 \mathrm{~cm}$ away. A red light-emitting diode (LED; $2.0 \mathrm{~cd} / \mathrm{m}^{2}$ ) was positioned onto the center of the screen and served as the initial FP. Red target LEDs $\left(5.0 \mathrm{~cd} / \mathrm{m}^{2}\right)$ were positioned at $20^{\circ}$ to the right or left of the central FP. The screen was diffusely illuminated between trials to avoid dark adaptation. Each trial began with a 250-ms period of complete darkness. The FP appeared for 1,000 ms and then 1 of 2 events occurred. In the gap condition, the FP was extinguished and, after a gap period of $200 \mathrm{~ms}$, the eccentric stimulus appeared in the right or left visual field. In the overlap condition, the FP remained lit when the eccentric stimulus appeared. In the prosaccade task, participants were instructed to start each trial fixated on the central FP and then look toward the stimulus as soon as it appeared. In the antisaccade task, participants were instructed to look away from the eccentric stimulus to the opposite side. The eccentric stimulus remained illuminated for $1,000 \mathrm{~ms}$, after which all LEDs disappeared and the background illumination reappeared, indicating the end of that trial. Stimulus location (right or left) and fixation conditions (gap or overlap) were pseudo-randomly interleaved throughout each block of trials. Subjects were asked to repeat the instructions to the experimenter to ensure that they understood the paradigm before the onset of data collection.

\section{Recording and Analysis of Eye Movements}

Horizontal eye position was measured using DC-electrooculography (EOG). $\mathrm{Ag}-\mathrm{AgCl}$ electrodes were affixed bitemporally and a grounding electrode was placed in the center of the forehead. All experimental data were digitized at $1 \mathrm{kHz}$ using REX (ver 5.4; Hays et al., 1982) and analyzed off-line on a Sun Ultra 60 Sparc station.

Saccadic reaction time was defined as the time from stimulus appearance to initiation of the first saccade that exceeded $30 \%$ s. Saccades were scored as correct if the first movement after the appearance of the eccentric stimulus was $>5^{\circ}$ in amplitude and in the correct direction (i.e., toward the stimulus in the prosaccade task, away from the stimulus in the antisaccade task). Saccades were scored as incorrect if the first saccade after the appearance of the stimulus was in the wrong direction (i.e., away from the stimulus in the prosaccade, toward the stimulus in the antisaccade task). The mean SRT in the prosaccade and antisaccade tasks was computed from trials with reaction latencies between 90 and $1,000 \mathrm{~ms}$. These criteria served to eliminate anticipatory saccades and atypically long responses (Munoz et al., 1998). In addition, we measured express saccades (latency: $90-140 \mathrm{~ms}$ ), which are the shortest latency visually triggered saccades (Dorris et al., 1997; Fischer and Ramsperger, 1984; Munoz et al., 1998). Express saccades have latencies that approach the minimal afferent and efferent conduction times for visual information to reach the oculomotor system and to be translated into a rapid eye movement (Dorris et al., 1997; Pare and Munoz, 1996). Neurons in the superior colliculus receive inputs from sensory, motor, and cognitive inputs, and these inputs contribute to establishing specific levels of excitability among populations of collicular neurons (fixation and saccade) that result in the generation of express saccades.

The following parameters were computed for each condition (gap, overlap) and direction (right, left): the mean SRT for correct trials, the coefficient of variation $(\mathrm{CV})$ of SRT for correct trials $[(\mathrm{CV}=$ standard deviation $/$ mean $) \times 100]$, the percentage of express saccades, and the percentage of direction errors. Metric analyses for correct prosaccade trials were also carried out to determine the amplitude of the first saccade and the number of saccades made to reach the stimulus. For correct prosaccades that were restricted to $18^{\circ}$ to $21^{\circ}$ in amplitude, duration and peak velocity were also computed.

\section{Data Analysis}

The 2 experiments (prosaccade and antisaccade tasks) contained 2 within-subject factors: fixation state (gap vs overlap) and direction (right vs left); and 1 between-group factor: clinical pathology (FASD vs control). All dependent measures (SRT, CV, express saccades, direction errors) were analyzed using ANOVA with $\alpha$ set at 0.05 . Two-tailed, unpaired Student's $t$-tests were conducted and corrected with Welch's approximation when the assumption for homogeneity of variance was not met. We will focus on descriptions of the relevant statistical parameters for comparisons and interactions that occurred between the control and FASD groups.

\section{RESULTS}

\section{$S R T$}

Figure 2 depicts the cumulative distribution of reaction times for correct responses (positive values) and direction errors (negative values) for control and FASD children in the prosaccade (Fig. 2A and 2C) and antisaccade (Fig. 2B and 2D) tasks in both the gap (Fig. 2A and 2B) and overlap (Fig. 2C and 2D) conditions. Controls were faster to react and initiate saccades in both the prosaccade and antisaccade trials (solid traces lead dashed traces). The gray boxes in Fig. 2 depict the express saccade epoch, 90 to $140 \mathrm{~ms}$ after stimulus appearance. In the prosaccade task, the FASD group made more direction errors and fewer express saccades compared with controls. In the antisaccade task, FASD subjects made more direction errors (although not significant); however, these errors were generated at very different times. The majority of direction errors made by controls were triggered in the express saccade range (gray box), while FASD direction errors were triggered later.

The ANOVA revealed the following for dependent measures (SRT, CV, express saccades, direction errors). FASD children had slower SRT compared with controls $[F(1,20)=20.9, \quad p<0.001]$. Consistent with previous studies, the mean SRT was increased for antisaccades compared with prosaccades $[F(1,20)=47.7, p<0.001]$, and in the overlap condition compared with the gap condition $[F(1,20)=94.2, p<0.001]$ for all groups. There were no significant directional effects.

Figures 3 and 4 summarize the data from the prosaccade and antisaccade tasks, respectively. In both the gap (Figs. 3A, 4A) and overlap (Figs. 3B, 4B) conditions, the mean SRT was elevated in the FASD group compared with controls in the prosaccade task [gap: $t_{(20)}=5.8, p<0.001$; overlap: $\left.t_{(20)}=4.6, p<0.001\right]$ and in the antisaccade task [gap: $t_{(20)}=2.5, p<0.05$; overlap: $t_{(20)}=2.3, p<0.05$ ]. The antieffect (antisaccade SRT-prosaccade SRT) for children with FASD was not significantly different from control children $\left[t_{(20)}=0.95, p=0.35\right]$.

The gap effect (overlap SRT-gap SRT) for prosaccades ranged between 19 to $95 \mathrm{~ms}$ for control subjects and 28 to $177 \mathrm{~ms}$ for FASD children, and there was no significant difference between groups $\left[t_{(20)}=0.02, p=0.98\right]$. Similarly, the gap effect for antisaccades was also not significantly different between controls and FASD $\left[t_{(20)}=0.16\right.$, $p=0.87$, and ranged between -2 to $75 \mathrm{~ms}$ and -55 to $100 \mathrm{~ms}$ for control and FASD children, respectively. 

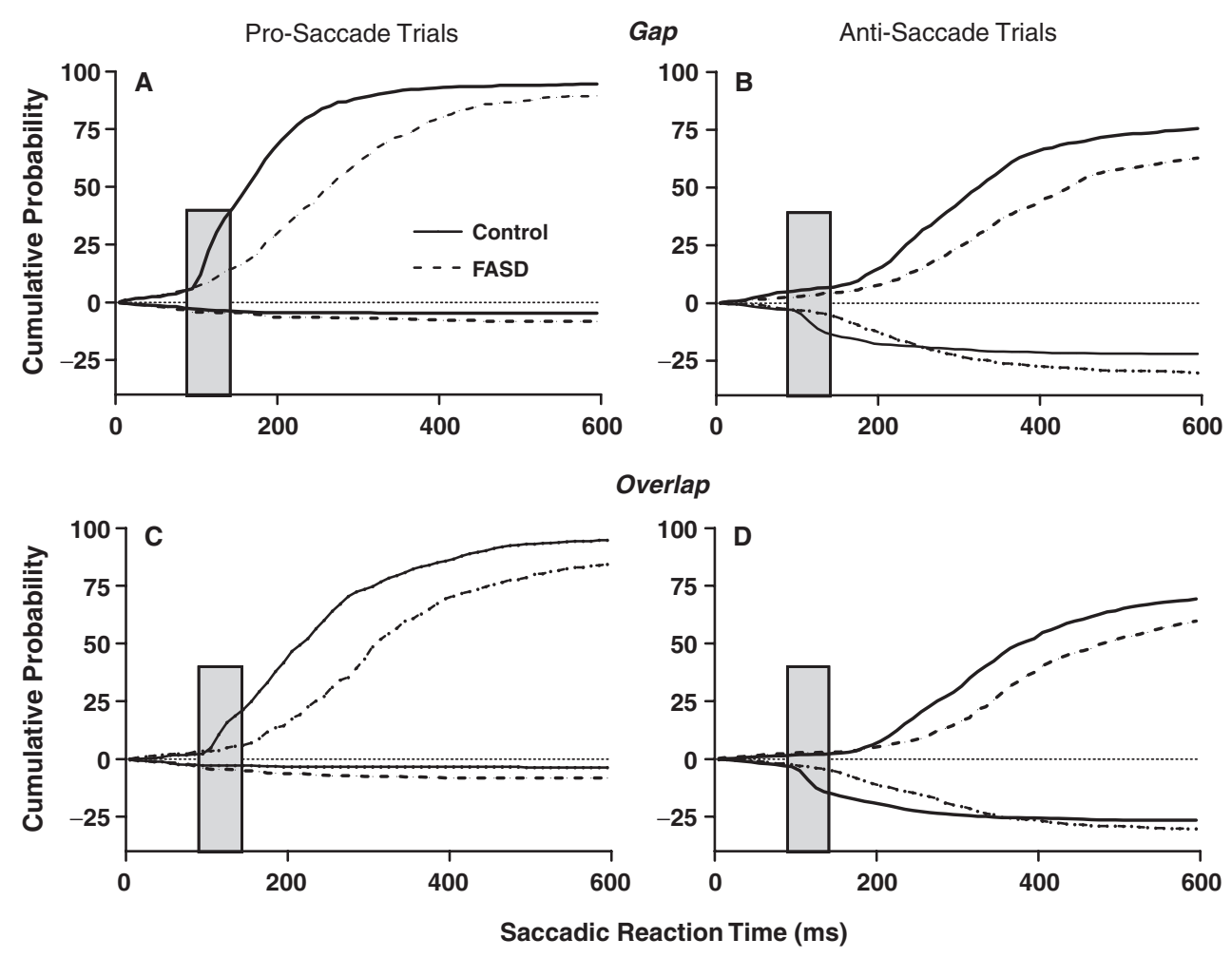

Fig. 2. Cumulative distribution of saccadic reaction times for correct responses (positive values on the ordinate) and direction errors (negative values on ordinate) for prosaccade (A, C) and antisaccade (B, D) trials in the gap (A, B) and overlap (C, D) conditions. Dashed traces, fetal alcohol spectrum disorders (FASD) data; solid traces, control data. The gray box highlights the express saccade epoch.

There was a significant interaction for group across direction and fixation condition $[F(1,20)=5.81, p<0.05]$. In control subjects, SRT in the prosaccade task were faster for leftward saccades, whereas faster SRT in the antisaccade task were dependent on rightward saccades. In contrast, for the FASD group, faster SRT in the prosaccade task were dependent on rightward saccades, and direction had no effect on SRT in antisaccades.

\section{CV}

The CV normalizes for intrasubject variability in SRT. Only task was statistically significant for the $\mathrm{CV}$, indicating increased variability in SRT for the antisaccade task compared with the prosaccade task $[F(1,20)=8.5, p<0.01]$. There were no significant differences between group $[F(1,20)=2.0, p=0.17]$, fixation condition $[F(1,20)=0.9$, $p=0.77]$, or direction $[F(1,20)=1.0, p=0.34]$.

Figure $3 \mathrm{C}$ and $3 \mathrm{D}$ illustrate the intrasubject variability in SRT for prosaccades, expressed as the CV. There was no significant difference between controls and FASD in $\mathrm{CV}$ for the gap $\left[t_{(20)}=2.3, p=0.24\right]$ and overlap $\left[t_{(20)}=0.04, p=0.97\right]$ conditions (Fig. $3 \mathrm{C}$ and 3D). Figure $4 \mathrm{C}$ and $4 \mathrm{D}$ illustrate $\mathrm{CV}$ for control and FASD children in the antisaccade task. Coefficient of variation was elevated for the FASD children in the gap condition $\left[t_{(20)}=2.3\right.$, $p<0.05]$, and the same trend was present in the overlap condition $\left[t_{(20)}=1.4, p=0.18\right]$.

\section{Express Saccades}

The ANOVA of dependent measures revealed significant differences between group, task, and fixation conditions in express saccades. The control group generated a higher percentage of express saccades compared with the FASD children $[F(1,20)=9.9, p<0.01]$. A higher percentage of express saccades were also generated in the prosaccade task compared with the antisaccade task $[F(1,20)=21.7$, $p<0.001]$ and for the gap condition compared with the overlap condition $[F(1,20)=35.5, p<0.001]$. There were no significant differences in direction $[F(1,20)=0.1, p=0.78]$.

There was an unexpected and significant decrease in the percentage of express saccades (Fig. 3E and 3F) by the FASD children in both the gap $\left[t_{(14)}=4.0, p<0.01\right]$ and overlap $\left[t_{(12)}=3.1, p<0.01\right]$ conditions. Express saccades are not generated in the antisaccade paradigm, and saccades with SRT latencies comparable with the express epoch represent direction errors that are made toward the stimulus (see Fig. 2B and 2D).

There was an interaction between group and task $[F(1,20)=13.1, p<0.01]$ such that increased percentage of express saccades depended on the gap condition in the control children, whereas this relationship was virtually absent in FASD children. There was also an interaction for group across task and fixation condition $[F(1,20)=5.85$, $p<0.05]$, which revealed that increased express saccades in controls was dependent on prosaccades in the gap condition. While there was no evidence, an interaction 

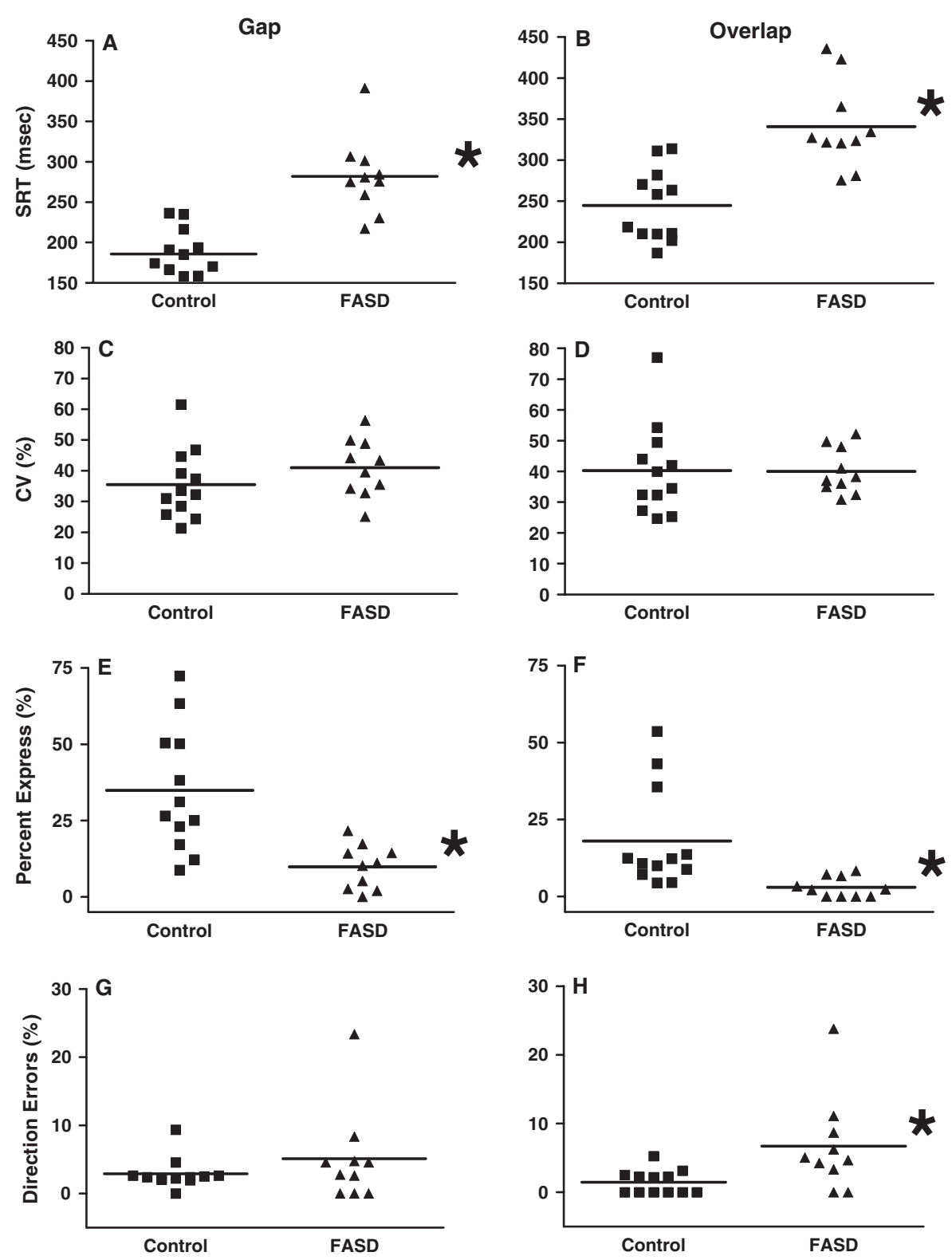

Fig. 3. Quantification of parameters in the gap $(\mathbf{A}, \mathbf{C}, \mathbf{E}, \mathbf{G})$ and overlap $(\mathbf{B}, \mathbf{D}, \mathbf{F}, \mathbf{H})$ conditions for the prosaccade task. (A and B): mean saccadic reaction times (SRTs) for correct responses. (C and D): coefficient of variation (SD of SRT/mean SRT $\times 100 \%$ ). (E and F): percentage of express saccades (SRT: $90-140$ $\mathrm{ms})$. ( $\mathrm{G}$ and $\mathrm{H})$ : percentage of direction errors. ${ }^{*} p<0.05$ compared with control subjects.

between fixation condition and group approached statistical significance $[F(1,20)=3.80, p=0.07]$.

\section{Direction Errors}

There was a statistically significant increase in the percent of direction errors in task $[F(1,20)=36.1, p<0.001]$. Although there was no evidence for differences in group $[F(1,20)=3.5, p=0.08]$ or fixation condition $[F(1,20)$, $p=0.07]$, both dependent measures approached statistical significance. There was no significant difference for direction $[F(1,20)=0.17, p=0.68]$.

An unexpected finding was the increase in the percent of direction errors on prosaccade trials in the overlap condition (Fig. $3 \mathrm{H}$ ) for the FASD group compared with controls $\left[t_{(10)}=2.3, p<0.05\right]$, which did not reach significance in the gap condition $\left[t_{(20)}=1.0, p=0.31\right]$ (Fig. 3G). The percentage of direction errors in the antisaccade task is illustrated in Fig. 4E and 4F. Although FASD children made more direction errors in the antisaccade task, this failed to reach statistical significance [gap: $t_{(12)}=1.5$, $p=0.16$; overlap: $\left.t_{(13)}=1.2, p=0.26\right]$.

\section{Metrics}

We also investigated saccade metrics for the saccades made in the prosaccade task (Table 2). There were no differences between control and FASD subjects for amplitude of the first saccade to stimulus $[F(1,20)=1.69, p=0.21]$ or the number of saccades $[F(1,20)=2.37, p=0.139]$. For 

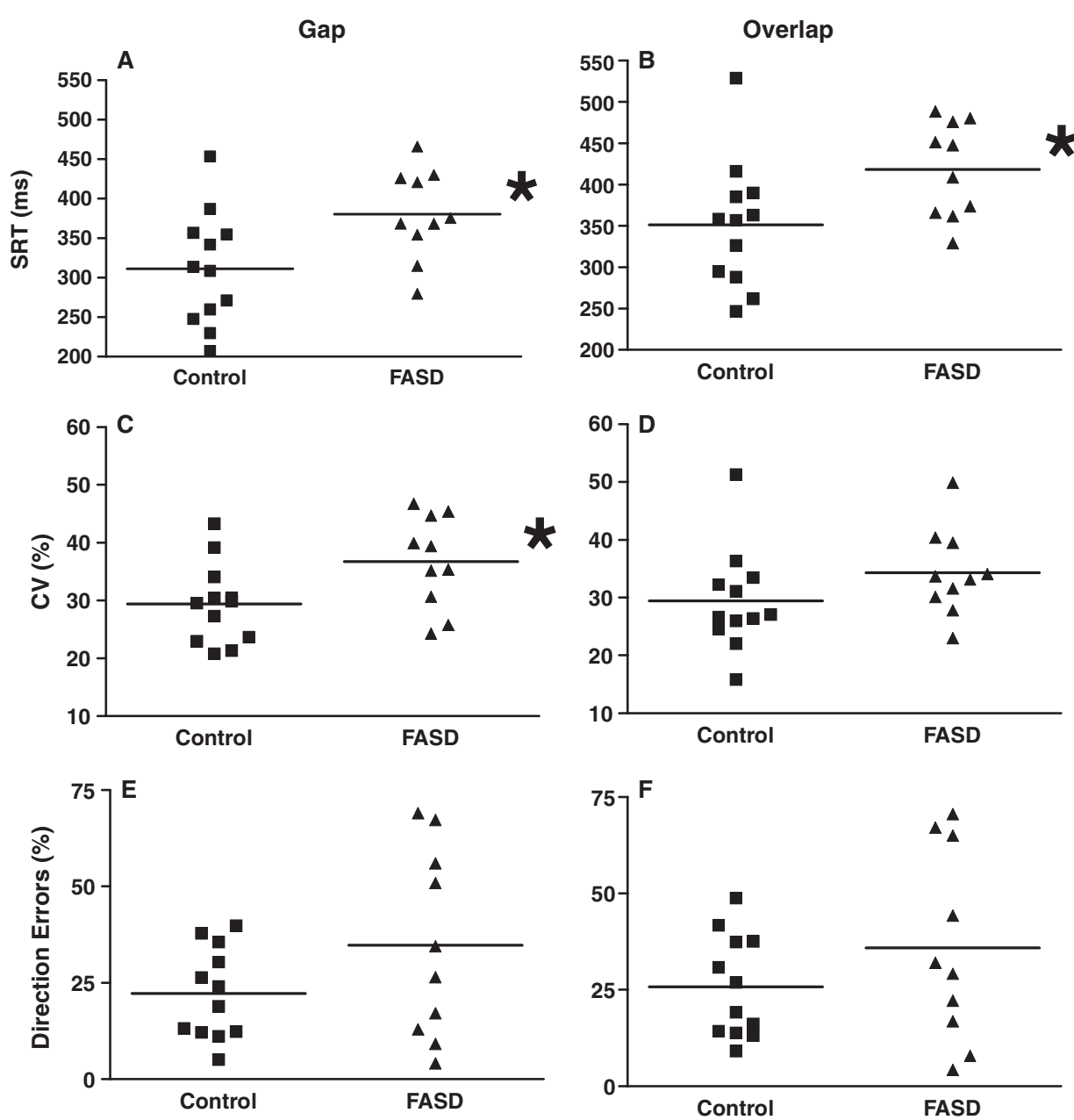

Fig. 4. Quantification of parameters in the gap (A, C, E) and overlap (B, D, F) conditions for the antisaccade task. (A and B): mean saccadic reaction times (SRTs) for correct responses. (C and D): coefficient of variation (SD of SRT/mean SRT $\times 100 \%$ ). (E and F): percentage of direction errors. ${ }^{*} p<0.05$ compared with control subjects.

saccades between $18^{\circ}$ and $21^{\circ}$ in amplitude, there was a strong trend toward an increase in duration $[F(1,20)=3.76$, $p=0.07]$, and reduction in saccade velocity $[F(1,20)=3.08$, $p=0.10]$ for the FASD subjects compared with controls. It is expected that with a larger sample size, the latter 2 measures would reach statistical significance.

\section{DISCUSSION}

This study shows for the first time that saccadic eye movement experiments can be conducted in children with

Table 2. Saccade Metrics from the Immediate Prosaccade Task

\begin{tabular}{lcccc}
\hline & $\begin{array}{c}\text { Amplitude } \\
\left({ }^{\circ}\right)\end{array}$ & $\begin{array}{c}\text { Number of } \\
\text { saccades }\end{array}$ & $\begin{array}{c}\text { Duration } \\
(\mathrm{ms})\end{array}$ & $\begin{array}{c}\text { Peak velocity } \\
(\%)\end{array}$ \\
\hline $\begin{array}{l}\text { Gap condition } \\
\text { Control }\end{array}$ & $19 \pm 1$ & $1.22 \pm 0.05$ & $75 \pm 5$ & $471 \pm 25$ \\
FASD & $19 \pm 1$ & $1.09 \pm 0.06$ & $88 \pm 5$ & $398 \pm 27$ \\
$\begin{array}{l}\text { Overlap condition } \\
\text { Control }\end{array}$ & $19 \pm 1$ & $1.15 \pm 0.04$ & $76 \pm 5$ & $445 \pm 24$ \\
FASD & $20 \pm 1$ & $1.07 \pm 0.05$ & $89 \pm 5$ & $394 \pm 26$ \\
\hline
\end{tabular}

FASD, fetal alcohol spectrum disorders.
FASD, and suggests that these tests may provide a sensitive indicator of the brain injury associated with FASD. Significant differences between the performance of FASD subjects and control subjects were demonstrated. Children with FASD exhibited: (1) increased reaction times; (2) a decreased ability to trigger express saccades; (3) an increase in direction errors in the prosaccade task; and (4) no significant increase in direction errors in the antisaccade task. Therefore, we conclude that these data support our initial hypothesis that eye movement experiments can be used to assess executive function in children with FASD. These data are first discussed and related to other clinical groups with developmental disabilities. We then review saccade neural circuitry and speculate about FASD pathophysiology.

\section{Eye Movement Abnormalities in Developmental Disorders}

A frequent comorbidity for individuals with FASD is ADHD (Table 1); however, differences in the neurocognitive and behavioral deficits that characterize these 2 disorders have previously been reported (Coles et al., 
1997). Several saccadic eye movement studies have been conducted in the ADHD population using prosaccade and antisaccade paradigms (Aman et al., 1998; Cairney et al., 2001; Hanisch et al., 2006; Klein et al., 2003; Mostofsky et al., 2001; Munoz et al., 2003). These studies have revealed contradictory results due largely to discrepancies in methodology. Two studies with rigorous procedural control and statistical analyses reveal that children with ADHD produce significantly more direction errors in the antisaccade task compared with controls (Klein et al., 2003; Munoz et al., 2003). However, these studies also present contrasting results regarding the occurrence of express saccades. Munoz et al. (2003) described a trend toward ADHD children producing more express saccades compared with controls. In contrast, Klein et al. (2003) found that children with ADHD exhibited a reduced proportion of express saccades in the gap condition.

Although comorbid ADHD existed in 8 of the 10 cases of FASD, the emerging profile for saccadic eye movement abnormalities in FASD is markedly different from what is observed in children with a diagnosis of ADHD (Klein et al., 2003; Munoz et al., 2003). Children with FASD failed to generate express saccades, even among direction errors in the antisaccade task (see Fig. 2). In addition, they made more direction errors in the prosaccade task, while ADHD children made more direction errors in the antisaccade task only. The increased percentage of direction errors in the prosaccade task exhibited in FASD is highly unusual and not observed in ADHD. Direction errors in the antisaccade tasks tend to be initiated immediately following target appearance, within the express epoch for both control (Munoz et al., 1998) and ADHD (Munoz et al., 2003) subjects, while FASD subjects produce direction errors with much longer latencies (see Fig. 2B and 2D). Future studies will be important for exploring the potential use of saccadic eye movement experiments for contrasting FASD and ADHD. The marked differences we report in express saccade occurrence and pattern of direction errors provide important clues and definitely suggest dramatic differences in underlying pathophysiology.

Using the same tasks described here, LeVasseur et al. (2001) demonstrated that individuals with TS have increased SRTs, no significant increase in direction errors in the antisaccade task, and a decrease in the percentage of express saccades. Although this pattern of deficits resembles the data observed in FASD, children with FASD make more direction errors in the prosaccade task, while TS subjects do not. In addition, individuals with TS display no significant differences in saccadic velocity or duration, while the amplitude of the first saccade was smaller and more saccades were generated to move to the target. These observations contrast the trends observed in FASD subjects, in which a decrease in saccadic velocity and an increase in saccadic duration approached significance. These differences between TS and FASD suggest very different patterns of pathophysiology in these 2 disorders.

Of interest, our observations on FASD are not attributable to developmental delay. The normative data generated by Munoz et al. (1998) revealed that young children (ages 5-8) initiated more express saccades than what we observed in FASD. The increase in the occurrence of express saccades among young children suggests that they have poor control over visual fixation, leading to the generation of excessive automatic (reflexive) saccades. Fixation ability improves during normal maturation. The virtual absence of express saccades in the FASD children must therefore be due to a deficit that cannot be explained simply by a delay in normal development.

\section{Neural Circuitry}

The neural circuitry underlying saccadic eye movements has been well characterized (Munoz and Everling, 2004; Munoz and Schall, 2004; Pierrot-Deseilligny et al., 2004; Schall, 2004; Scudder et al., 2002; Sparks, 2002). The dorsolateral prefrontal cortex (DLPFC) is involved in executive function, spatial working memory, and importantly, the suppression of unwanted saccades, while the frontal eye fields (FEF) play a crucial role in the execution of voluntary saccades. Punctate lesions to the DLPFC lead to increased direction errors in the antisaccade task (Gaymard et al., 1998; Guitton et al., 1985). Damage to the FEF is correlated with prolonged SRT (Rivaud et al., 1994). In the monkey, reversible inactivation of the FEF leads to increased SRT, decreased saccadic velocity, and increased saccadic duration (Dias and Segraves, 1999; Sommer and Tehovnik, 1997). Reversible inactivation of the DLPFC results in impairments in reflexive saccadic inhibition, leading to increased direction errors in the antisaccade task (Condy et al., 2007). These findings are similar to those obtained in our study, and suggest that DLPFC and FEF dysfunction may account, in part, for the oculomotor deficits observed in FASD. In FASD children, there appears to be global frontal lobe damage that may include the FEF and DLPFC, which would account for the increased SRT and excessive numbers of nonreflexive (longer-latency) direction errors in the antisaccade task.

Damage to frontal lobes has been well documented in the FASD population (Sowell et al., 2002b; Wass et al., 2001), and this has been correlated with deficits in impulsivity, response inhibition, and judgment (Rasmussen, 2005). While our study failed to reveal deficits in impulsivity (increased reflexive direction errors in the antisaccade task), it was apparent that children with FASD executed more disorganized responses that reflected increase direction errors in both the prosaccade and antisaccade tasks. Additionally, their inability to turn off the fixation mechanism in advance precluded their capacity to generate express saccades. These observations suggest that FASD 
children have difficulty integrating multiple instructions into a correct sequence of actions, which is consistent with the known deficits in planning ability and/or response inhibition that are associated with FASD.

The relationship between DLPFC and express saccades has been previously investigated using single pulse transcranial magnetic stimulation (TMS) and saccadic eye movement experiments (Muri et al., 1999). The reduction in the SRT following TMS of the DLPFC was attributed to an increase in the percentage of express saccades. The authors suggested that this effect was mediated by either direct activation of the superior colliculus (Leichnetz, 1981) or disinhibition of the superior colliculus via the basal ganglia (Hikosaka et al., 2000). Thus, alterations in the pattern of signaling from DLPFC to superior colliculus may result in deficient express saccade generation. Deficits in FEF function can lead to increased latencies, which could further contribute to the increase in prosaccade duration and decrease in prosaccade velocity. Taken together, these results suggest that global deficits among regions of the frontal cortex lead to a specific pattern of eye movement behavior that is unique to the FASD population consisting of increased SRT and decreased percentage of express saccades. One plausible explanation for these observed deficits is increased inhibition within the frontal cortex. Studies conducted in experimental animal models have shown that chronic prenatal ethanol exposure induces an up-regulation in the expression of $\mathrm{GABA}_{\mathrm{A}}$ receptors in the cerebral cortex of postnatal offspring (Bailey et al., 1999, 2001), which would be expected to increase inhibitory tone.

\section{Accumulator Model}

Several models have been proposed to explain the variability of reaction time (Luce, 1986; Munoz and Schall, 2004; Nazir and Jacobs, 1991; Ratcliff, 2006; Trappenberg et al., 2001). The accumulator model is useful for interpreting the neurophysiological and behavioral data related to the initiation of saccades in clinical disorders (Munoz et al., 2007). This model is based on the supposition that to initiate movement, neural activity must grow to exceed a given threshold (Fig. 5). In the brain, this function may be represented by the presaccadic activity of saccade neurons in the FEF and superior colliculus (Munoz and Schall, 2004). These neurons can be activated in advance of target presentation, as well as activated directly by target presentation in a neuron's response field (posttarget activation). Three sources have been identified as contributors to variability in reaction time: baseline, threshold, and rate of rise (from baseline to threshold). Thus, pretarget (baseline) and posttarget (rate of rise) information processing can alter the accumulation of activity toward threshold to initiate action. In Fig. 5, the vertical gray box represents the time of the visual response on saccade neurons contralateral and ipsilateral to the side of the target. Pretarget activity (to the left of the target appearance in Fig. 5) is influenced by fixation disengagement and target predictability (Munoz et al., 2000).

The accumulator model has been used to account for deficits in ADHD, TS, and Parkinson's disease (Munoz et al., 2007). The mean SRT was elevated in ADHD, more direction errors were generated in the antisaccade task compared with controls, and there was a trend toward more express saccades and excessive variability in SRT. These observations suggest poor control over pretarget activity. Excessive pretarget activity can combine with the phasic visual response on the contralateral side to trigger express saccades in the prosaccade task (Fig. 5A, black dashed traces) and reflexive direction errors in the antisaccade task (Fig. 5B, black dotted trace). Attention-deficit hyperactivity disorder behavior can be accounted for by deficits in managing pretarget excitability. Posttarget factors appeared somewhat normal in ADHD (Munoz et al., 2007). LeVasseur et al. (2001) suggested that the increased SRT and reduced occurrence of express saccades in TS may be due to a reduction in pretarget activity leading to delayed threshold crossing (similar to the gray traces in Fig. 5).

Recall that children with FASD exhibit increased SRT, a decreased ability to trigger express saccades, increased direction errors in the prosaccade task, and no significant increase in direction error in the antisaccade task. We speculate that FASD children have reduced excitability (reduced pretarget activity) in the saccade-generating circuit (Fig. 5, gray traces below the black traces). As a consequence, in the prosaccade task, an express saccade is never triggered, while in the antisaccade task, no direction errors are triggered at express saccade latency. Instead, the reduced pretarget baseline leads to prolonged reaction times. A striking difference between FASD and both TS and ADHD was the increase in the occurrence of direction errors in the prosaccade task. Because of poor inhibitory control in FASD, inappropriate activity is allowed to increase toward threshold on the ipsilateral side of the brain (Fig. 5A, see arrow and dotted gray trace), leading to some direction errors in the prosaccade task, which is highly abnormal.

To initiate a correct antisaccade (Fig. 5B), activity must cross threshold on the ipsilateral side of the brain. If the pretarget activity is too high, the posttarget visual response on the contralateral side can contribute to drive the system over the threshold, triggering a reflexive direction error (Fig. 5B, dotted black trace). Because of excessive inhibition in FASD, reflexive direction errors are not triggered, but longer latency direction errors can occur (Fig. 5B, see arrow and dotted gray trace).

Although the specific mechanisms remain to be determined, our suggestions of reduced pretarget activity and accumulation of activity on the wrong side (i.e., ipsilateral side for prosaccades; contralateral side for antisaccades; see arrows in Fig. 5) are unique for FASD and are dramatically different from what is proposed for ADHD 
A
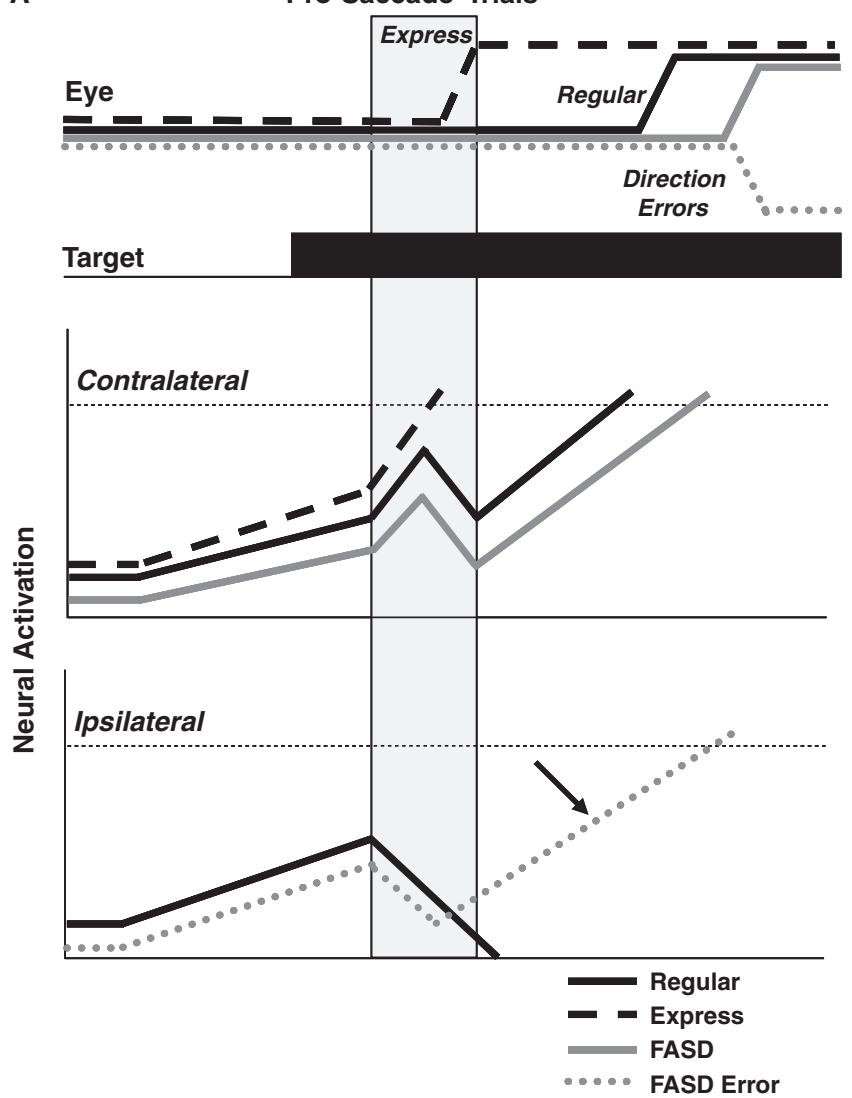

B

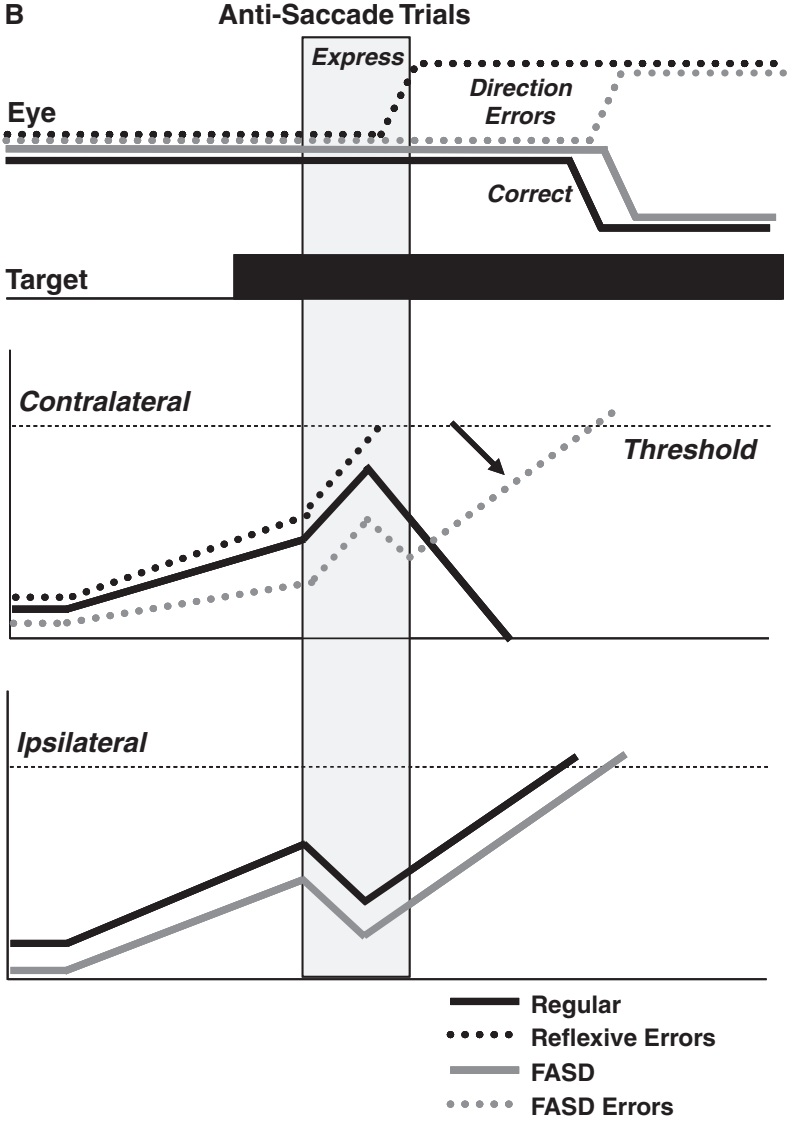

Fig. 5. Accumulator model to describe eye movement abnormalities in fetal alcohol spectrum disorders (FASD). Neural activity must grow to reach a given threshold to trigger a saccade. (A) In the prosaccade task, with sufficient pretarget activity, the visual response can lead to the immediate threshold crossing and trigger an express saccade (black dashed trace). Reduced pretarget activity leads to the initiation of regular-latency saccades (black solid trace). In FASD, pretarget activity is reduced, leading to delayed threshold crossing (gray solid trace). In addition, activity is allowed to increase toward the threshold on the ipsilateral side of the brain, leading to highly unusual direction errors in the prosaccade task (dotted gray trace). (B) To initiate a correct antisaccade, activity must cross threshold on the ipsilateral side of the brain. If the pretarget activity is too high, the posttarget visual response can contribute to drive the contralateral accumulator over the threshold, triggering a reflexive direction error (black dotted trace). In FASD, reflexive direction errors are not triggered but longer latency errors can occur (gray dotted trace).

subjects (Munoz et al., 2007). As discussed above, this may be the result of an up-regulation in the expression of GABA $_{\mathrm{A}}$ receptors (Bailey et al., 1999, 2001), which would lead to increased inhibition. Such a mechanism could lead to oculomotor abnormalities, and explain the reduction in baseline activity among saccade neurons (Fig. 5). Although FASD subjects do not appear to be impaired in their ability to inhibit automatic visually triggered saccades in the antisaccade task, it is clear that they do have deficits is suppressing activity calling for inappropriate saccades (direction errors) at longer latency. The exact mechanism by which increased inhibition translates into these abnormal processes remains to be fully determined.

\section{Study Limitations}

As the sample size was small, it was not possible to confirm with any certainty the contribution that medication and/or comorbidity may have had to the findings presented here. It appears from the scatter plots that the effects reported in this study were not driven by lone sub- jects, who were considered outliers (Figs. 3 and 4). Still, the importance of these possible confounders is noted and will be more fully investigated in future larger-scale studies.

\section{CONCLUSION}

To the best of our knowledge, this study is the first of its kind to evaluate control of saccadic eye movements in children with FASD. A preliminary report of eye movement recording in young adults with prenatal alcohol exposure reported similar effects (Willford et al., 2005). Currently, a larger-scale study is underway to characterize more fully the sensitivity and specificity of these deficits in the FASD population. The results from this pilot study suggest that measuring saccadic eye movement behavior is a promising research and diagnostic tool for evaluating the brain injury resulting from prenatal ethanol exposure.

\section{ACKNOWLEDGMENTS}

We thank Irene Armstrong for her assistance in handling the statistical analyses, the Munoz lab for commenting 
on an earlier version of the manuscript, and all of our volunteer subjects. We also thank Dr. Brenda Stade for her assistance in recruiting 2 subjects from the FAS diagnostic clinic at St. Michael's Hospital in Toronto, ON.

\section{REFERENCES}

Aman CJ, Roberts RJ Jr., Pennington BF (1998) A neuropsychological examination of the underlying deficit in attention deficit hyperactivity disorder: frontal lobe versus right parietal lobe theories. Dev Psychol 34:956-969.

Armstrong IT, Munoz DP (2003) Inhibitory control of eye movements during oculomotor countermanding in adults with attention-deficit hyperactivity disorder. Exp Brain Res 152:444-452.

Astley SJ, Clarren SK (2000) Diagnosing the full spectrum of fetal alcohol-exposed individuals: introducing the 4-digit diagnostic code. Alcohol Alcohol 35:400-410.

Bailey CD, Brien JF, Reynolds JN (1999) Altered GABA(A)-benzodiazepine receptor number and pharmacology in the adult guinea pig cerebral cortex after chronic prenatal ethanol exposure. Alcohol Clin Exp Res 23:1816-1824.

Bailey CD, Brien JF, Reynolds JN (2001) Chronic prenatal ethanol exposure increases $\mathrm{GABA}(\mathrm{A})$ receptor subunit protein expression in the adult guinea pig cerebral cortex. J Neurosci 21:4381-4389.

Cairney S, Maruff P, Vance A, Barnett R, Luk E, Currie J (2001) Contextual abnormalities of saccadic inhibition in children with attention deficit hyperactivity disorder. Exp Brain Res 141:507-518.

Chan F, Armstrong IT, Pari G, Riopelle RJ, Munoz DP (2005) Deficits in saccadic eye-movement control in Parkinson's disease. Neuropsychologia 43:784-796.

Chudley AE, Conry J, Cook JL, Loock C, Rosales T, LeBlanc N (2005) Fetal alcohol spectrum disorder: Canadian guidelines for diagnosis. Can Med Assoc J 172:S1-S21.

Clarren SK, Smith DW (1978) The fetal alcohol syndrome. N Engl J Med 298:1063-1067.

Coles CD, Platzman KA, Raskind-Hood CL, Brown RT, Falek A, Smith IE (1997) A comparison of children affected by prenatal alcohol exposure and attention deficit, hyperactivity disorder. Alcohol Clin Exp Res 21:150-161.

Condy C, Wattiez N, Rivaud-Pechoux S, Tremblay L, Gaymard B (2007) Antisaccade deficit after inactivation of the principal sulcus in monkeys. Cereb Cortex 17:221-229.

Connor PD, Sampson PD, Bookstein FL, Barr HM, Streissguth AP (2000) Direct and indirect effects of prenatal alcohol damage on executive function. Dev Neuropsychol 18:331-354.

Crawford TJ, Henderson L, Kennard C (1989) Abnormalities of nonvisually-guided eye movements in Parkinson's disease. Brain 112 (part 6): 1573-1586.

Crawford TJ, Higham S, Renvoize T, Patel J, Dale M, Suriya A, Tetley S (2005) Inhibitory control of saccadic eye movements and cognitive impairment in Alzheimer's disease. Biol Psychiatry 57:1052-1060.

Currie J, Joyce S, Maruff P, Ramsden B, McArthur-Jackson C, Malone V (1993) Selective impairment of express saccade generation in patients with schizophrenia. Exp Brain Res 97:343-348.

Dias EC, Segraves MA (1999) Muscimol-induced inactivation of monkey frontal eye field: effects on visually and memory-guided saccades. J Neurophysiol 81:2191-2214.

Dorris MC, Pare M, Munoz DP (1997) Neuronal activity in monkey superior colliculus related to the initiation of saccadic eye movements. $\mathbf{J}$ Neurosci 17:8566-8579.

Fischer B, Biscaldi M, Gezeck S (1997) On the development of voluntary and reflexive components in human saccade generation. Brain Res 754:285-297.

Fischer B, Ramsperger E (1984) Human express saccades: extremely short reaction times of goal directed eye movements. Exp Brain Res 57:191-195.
Funahashi S (2001) Neuronal mechanisms of executive control by the prefrontal cortex. Neurosci Res 39:147-165.

Gaymard B, Ploner CJ, Rivaud S, Vermersch AI, Pierrot-Deseilligny C (1998) Cortical control of saccades. Exp Brain Res 123:159-163.

Green CR, Munoz DP, Reynolds JN (2004) Evaluation of saccadic eye movement as a new diagnostic tool for fetal alcohol syndrome (FAS). Perinatal Investigators 28th Annual Meeting, Kingston, Ontario, Canada.

Green CR, Munoz DP, Reynolds JN (2005) Saccadic eye movements: a novel diagnostic approach to fetal alcohol syndrome (FAS). Society for Neuroscience 35th Annual Meeting, Washington, DC.

Green CR, Munoz DP, Reynolds JN (2006) Children with fetal alcohol spectrum disorders display a unique pattern of deficits in eye movement behaviours. International Society for Biomedical Research on Alcoholism, Sydney, Australia.

Guitton D, Buchtel HA, Douglas RM (1985) Frontal lobe lesions in man cause difficulties in suppressing reflexive glances and in generating goal-directed saccades. Exp Brain Res 58:455-472.

Hallett PE (1978) Primary and secondary saccades to goals defined by instructions. Vision Res 18:1279-1296.

Hanisch C, Radach R, Holtkamp K, Herpertz-Dahlmann B, Konrad K (2006) Oculomotor inhibition in children with and without attentiondeficit hyperactivity disorder (ADHD). J Neural Transm 113:671-684.

Hays AV, Richmond RJ, Optician LM (1982) A UNIX-based multiple process system for real-time data acquisition and control. WESCON $2: 1-10$.

Hikosaka O, Takikawa Y, Kawagoe R (2000) Role of the basal ganglia in the control of purposive saccadic eye movements. Physiol Rev 80:953-978.

Katzung BG (1998) Basic \& Clinical Pharmacology. Appleton \& Lange, Stamford.

Kimmig H, Haussmann K, Mergner T, Lucking CH (2002) What is pathological with gaze shift fragmentation in Parkinson's disease? J Neurol 249:683-692.

Klein CH, Raschke A, Brandenbusch A (2003) Development of pro- and antisaccades in children with attention-deficit hyperactivity disorder (ADHD) and healthy controls. Psychophysiology 40:17-28.

Kopera-Frye K, Dehaene S, Streissguth AP (1996) Impairments of number processing induced by prenatal alcohol exposure. Neuropsychologia 34:1187-1196.

Koren G, Nulman I, Chudley AE, Loock C (2003) Fetal alcohol spectrum disorder. Can Med Assoc J 169:1181-1185.

Le Heron CJ, MacAskill MR, Anderson TJ (2005) Memory-guided saccades in Parkinson's disease: long delays can improve performance. Exp Brain Res 161:293-298.

Leichnetz GR (1981) The prefrontal cortico-oculomotor trajectories in the monkey. J Neurol Sci 49:387-396.

Leigh RJ, Kennard C (2004) Using saccades as a research tool in the clinical neurosciences. Brain 127:460-477.

Leigh RJ, Zee DS (1999) The Neurology of Eye Movements. Davis, Philadelphia, PA.

LeVasseur AL, Flanagan JR, Riopelle RJ, Munoz DP (2001) Control of volitional and reflexive saccades in Tourette's syndrome. Brain 124:2045-2058.

Lezak MD (1995) Neuropsychological Assessment, 3rd ed., Oxford University Press Inc., New York.

Luce RD (1986) Response Times: Their Role in Inferring Elementary Mental Organization. Oxford Press, Oxford.

Mattson SN, Goodman AM, Caine C, Delis DC, Riley EP (1999) Executive functioning in children with heavy prenatal alcohol exposure. Alcohol Clin Exp Res 23:1808-1815.

Mattson SN, Schoenfeld AM, Riley EP (2001) Teratogenic effects of alcohol on brain and behavior. Alcohol Res Health 25:185-191.

Mostofsky SH, Lasker AG, Cutting LE, Denckla MB, Zee DS (2001) Oculomotor abnormalities in attention deficit hyperactivity disorder: a preliminary study. Neurology 57:423-430.

Munoz DP, Armstrong IT, Coe B (2007) Using eye movements to probe development and dysfunction, in Eye Movements: A Window on Mind 
and Brain (van Gompel RPG, Fischer MH, Murray WS, Hill RL eds), Elsevier, Oxford, UK, in press.

Munoz DP, Armstrong IT, Hampton KA, Moore KD (2003) Altered control of visual fixation and saccadic eye movements in attentiondeficit hyperactivity disorder. J Neurophysiol 90:503-514.

Munoz DP, Broughton JR, Goldring JE, Armstrong IT (1998) Agerelated performance of human subjects on saccadic eye movement tasks. Exp Brain Res 121:391-400.

Munoz DP, Dorris MC, Pare M, Everling S (2000) On your mark, get set: brainstem circuitry underlying saccadic initiation. Can J Physiol Pharmacol 78:934-944.

Munoz DP, Everling S (2004) Look away: the anti-saccade task and the voluntary control of eye movement. Nat Rev Neurosci 5: 218-228.

Munoz DP, Schall JD (2004) Concurrent, Distributed Control of Saccad Initiation in the Frontal Eye Field and Superior Colliculus, in The Superior Colliculus: New Approaches for Studying Sensorimotor Integration (Hall WC, Moschovakis A, eds), pp 55-82. CRC Press, Boca Raton, FL.

Muri RM, Rivaud S, Gaymard B, Ploner CJ, Vermersch AI, Hess CW, Pierrot-Deseilligny C (1999) Role of the prefrontal cortex in the control of express saccades. A transcranial magnetic stimulation study. Neuropsychologia 37:199-206.

Nazir TA, Jacobs AM (1991) The effects of target discriminability and retinal eccentricity on saccade latencies: an analysis in terms of variable-criterion theory. Psychol Res 53:281-289.

O'Driscoll GA, Depatie L, Holahan AL, Savion-Lemieux T, Barr RG, Jolicoeur C, Douglas VI (2005) Executive functions and methylphenidate response in subtypes of attention-deficit/hyperactivity disorder. Biol Psychiatry 57:1452-1460.

Pare M, Munoz DP (1996) Saccadic reaction time in the monkey: advanced preparation of oculomotor programs is primarily responsible for express saccade occurrence. J Neurophysiol 76:3666-3681.

Pierrot-Deseilligny C, Milea D, Muri RM (2004) Eye movement control by the cerebral cortex. Curr Opin Neurol 17:17-25.

Rasmussen C (2005) Executive functioning and working memory in fetal alcohol spectrum disorder. Alcohol Clin Exp Res 29: $1359-1367$.

Ratcliff R (2006) A theory of memory retrieval. Psychoanal Rev 85: 59-108.
Rivaud S, Muri RM, Gaymard B, Vermersch AI, Pierrot-Deseilligny C (1994) Eye movement disorders after frontal eye field lesions in humans. Exp Brain Res 102:110-120.

Salman MS, Sharpe JA, Eizenman M, Lillakas L, Westall C, To T, Dennis M, Steinbach MJ (2006) Saccades in children. Vision Res 46:1432-1439.

Schall JD (2004) On the role of frontal eye field in guiding attention and saccades. Vision Res 44:1453-1467.

Schonfeld AM, Mattson SN, Lang AR, Delis DC, Riley EP (2001) Verbal and nonverbal fluency in children with heavy prenatal alcohol exposure. J Stud Alcohol 62:239-246.

Scudder CA, Kaneko CS, Fuchs AF (2002) The brainstem burst generator for saccadic eye movements: a modern synthesis. Exp Brain Res 142:439-462.

Sommer MA, Tehovnik EJ (1997) Reversible inactivation of macaque frontal eye field. Exp Brain Res 116:229-249.

Sowell ER, Thompson PM, Mattson SN, Tessner KD, Jernigan TL, Riley EP, Toga AW (2002a) Regional brain shape abnormalities persist into adolescence after heavy prenatal alcohol exposure. Cereb Cortex 12:856-865.

Sowell ER, Thompson PM, Mattson SN, Tessner KD, Jernigan TL, Riley EP, Toga AW (2002b) Regional brain shape abnormalities persist into adolescence after heavy prenatal alcohol exposure. Cereb Cortex 12:856-865.

Sparks DL (2002) The brainstem control of saccadic eye movements. Nat Rev Neurosci 3:952-964.

Trappenberg TP, Dorris MC, Munoz DP, Klein RM (2001) A model of saccade initiation based on the competitive integration of exogenous and endogenous signals in the superior colliculus. J Cogn Neurosci $13: 256-271$

Wass TS, Persutte WH, Hobbins JC (2001) The impact of prenatal alcohol exposure on frontal cortex development in utero. Am J Obstet Gynecol 185:737-742.

Willford JA, Luna B, Day NL (2005) Prenatal alcohol exposure impairs inhibitory and cognitive control in young adulthood. Alcohol Clin Exp Res 29:128A.

Zanelli J, Simon H, Rabe-Hesketh S, Walshe M, McDonald C, Murray RM, Maccabe JH (2005) Eye tracking in schizophrenia: does the antisaccade task measure anything that the smooth pursuit task does not. Psychiatry Res 136:181-188. 